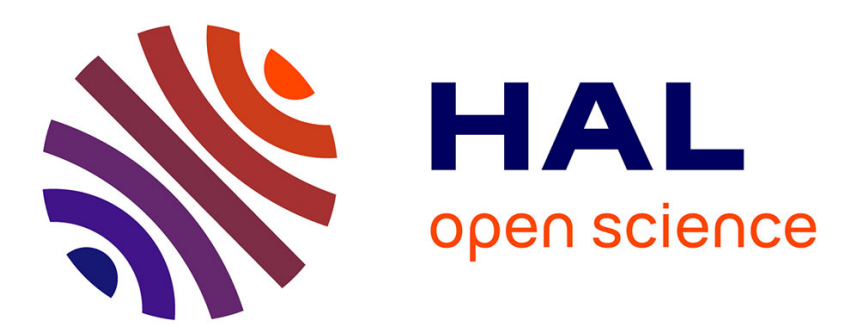

\title{
Advances in Cubic Silicon Carbide Surfaces and Self-Organized One Dimensional Sub-Nanoscale Objects \\ P. Soukiassian, F. Semond
}

\section{To cite this version:}

P. Soukiassian, F. Semond. Advances in Cubic Silicon Carbide Surfaces and Self-Organized One Dimensional Sub-Nanoscale Objects. Journal de Physique IV Proceedings, 1997, 07 (C6), pp.C6-101C6-113. 10.1051/jp4:1997609 . jpa-00255708

\section{HAL Id: jpa-00255708 https://hal.science/jpa-00255708}

Submitted on 1 Jan 1997

HAL is a multi-disciplinary open access archive for the deposit and dissemination of scientific research documents, whether they are published or not. The documents may come from teaching and research institutions in France or abroad, or from public or private research centers.
L'archive ouverte pluridisciplinaire HAL, est destinée au dépôt et à la diffusion de documents scientifiques de niveau recherche, publiés ou non, émanant des établissements d'enseignement et de recherche français ou étrangers, des laboratoires publics ou privés. 


\title{
Advances in Cubic Silicon Carbide Surfaces and Self-Organized One Dimensional Sub-Nanoscale Objects
}

\author{
P. Soukiassian ( ${ }^{1}$ ) and F. Semond \\ Commissariat à l'Énergie Atomique, DSM-DRECAM-SRSIM, Bâtiment 462, Centre d'Études de Saclay, \\ 91191 Gif-sur-Yvette cedex, France, and, Département de Physique, Université de Paris-Sud, \\ 91405 Orsay cedex, France
}

\begin{abstract}
We review the most recent advances into the knowledge and the understanding of cubic silicon carbide $\beta-S i C(100)$ surfaces. These investigations are based on the use of advanced experimental techniques such as photoemission spectroscopies with $x$-rays and synchrotron radiation sources, atom-resolved scanning tunneling microscopy, complementary low energy electron diffraction for characterisation, and state-of-the-art theoretical methods such as total energy $a b$-initio calculations using the Iocal density functional approximation and scanning tunneling microscopy image simulations. Surface preparation and morphology, atomic geometry, reconstructions, phase transition and the discovery of self-organized Si atomic lines having fascinating characteristics are described for Si-terminated $\beta$-SiC(100) surfaces. Such important issues as e.g. the role of defects or stress in surface atomic ordering will be addressed. These investigations brings deep insights into the knowledge and understanding of technologically important silicon carbide surfaces and reveal a novel aspect of $\mathrm{SiC}$ in its ability to be a very suitable material in nanotechnologies and micro/nano-electronics of the future.
\end{abstract}

\begin{abstract}
Résumé Nous passons en revue les récents progrès dans la connaissance et la compréhension des propriétés des surfaces $\beta$-SiC (100) du carbure de silicium cubique. Ces études sont basées sur l'utilisation de techniques expérimentales avancées telles que les spectroscopies de photoémission utilisant des sources de rayons $x$ ou le rayonnement synchrotron, la microscopie à effet tunnel (STM) à résolution atomique, la diffraction d'électrons lents comme outil de caractérisation, ainsi que des méthodes théoriques sophistiquées telles que des calculs $a b$ initio d'énergie totale utilisant la fonctionnelle de densité ou la simulation d'images STM. La préparation et la morphologie de surface, leur géométrie à l'échelle atomique, leurs reconstructions, les transitions de phase ainsi que la découverte de fils atomiques de Si qui s'auto-organisent sur les surfaces de $\beta$-SiC(100) avec des caractéristiques exceptionnelles sont décrites. Des questions importantes telles que le rôle des défauts et de la contrainte dans l'organisation, à l'échelle atomique, de la surface sont abordées. Ces études apportent des éléments nouveaux dans la compréhension des surfaces du carbure de silicium, un semiconducteur présentant un grand intérêt technologique. Enfin, elles révèlent un nouvel aspect du $\mathrm{SiC}$ en dévoilant ses grandes possibilités comme matériau potentiel pour les nanotechnologies et en micro/nano-électronique du futur.
\end{abstract}

\section{I - GENERAL PROPERTIES OF SILICON CARBIDE}

Silicon carbide (SiC) is an advanced IV-IV compound semiconductor which appears to be very interesting and promising from both fundamental and applied points of view [1-5]. In fact, this "refractory" semiconducting material belongs to the class of wide band gap semiconductors (together with diamond and group III nitrides), and has a very high thermal stability which is very useful for operations at rather elevated temperatures $\left(\geq 600^{\circ} \mathrm{C}\right.$ instead of $<150^{\circ} \mathrm{C} \mathrm{e.g}$. for silicon). These features make SiC especially suitable for high-power, high temperature, high voltage and high speed electronic devices and sensors [1$5]$. Depending whether it is in its cubic $(\beta)$ or hexagonal phase $(\alpha)$ crystallographic phase, its band gap could vary from $2.3 \mathrm{eV}$ to about $3.3 \mathrm{eV}$ which would allow to make homojunctions and superlattices based on the same material. In its cubic $\beta$-SiC phase, silicon carbide has a band gap of $2.3 \mathrm{eV}$ with a high breakdown electric field and a high saturated drift velocity [1-5]. For instance, its breakdown field, thermal conductance, band gap and saturated drift velocity are respectively x10 times, x3 times (making SiC comparable to copper), $\mathrm{x} 2$ times and $\mathrm{x} 2$ times larger than silicon [1-5]. In fact, when comparing average factors of merit for different semiconductors, Si being taken as the reference rates at 1, GaAs at 1.5 while $\mathrm{SiC}$ factor of merit is ranging from 1 to 3 orders of magnitude higher, outclassed only by diamond [1]. Fig. 1 shows best these striking differences by exhibiting the figures of merit for various conventional and novel semiconductors according to the criteria established by Keyes regarding high speed logic and high integration density devices [6] and by Johnson based on the performances for high power, high speed, high temperature and high voltage analogic devices [7].

(1) Also at: Department of Physics, Northern Illinois University, DeKalb, Illinois 60115-2854, U.S.A. 
High Power, High Temperature and High Speed Analogic Devices

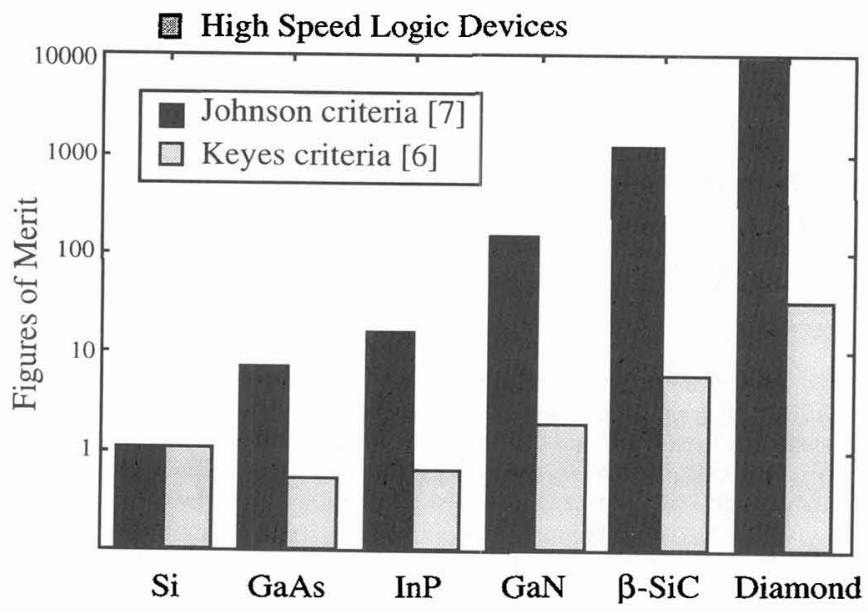

Fig. 1: Figures of merit of various semiconductors according to the criteria of Keyes [6] (high speed lo devices) and Johnson [7] (high power, high temperature and high speed analogic devices)

Also, due to its high thermal stability and chemical inertness, and its ability to resist to radiat: damages, silicon carbide is an especially attractive material to operate in hostile environments in particu when compared to silicon or to other compound semiconductors such as III-V. Actually, silicon carbidi expected to challenge silicon within the next decade in advanced microelectronics technology, w numerous applications in space, aeronautics, automotive or nuclear industries. In addition to its strc potential interest in microelectronics, optoelectronics and sensors, silicon carbide is also a ceramics hav very interesting mechanical properties with a very high hardness (surpassed by diamond and boron nitr: only) and is an especially suitable material in matrix composites [8]. Finally, $\mathrm{SiC}$ is one of the best $\mathrm{b}$ compatible material, in particular with human blood $[9,10]$. Among the key issues for practi microelectronics devices, low defect densities single crystal growth, high quality surfaces, surf $\varepsilon$ metallization and surface passivation are among the most important. However, in contrast to many otl elemental or compound semiconductors, silicon carbide has received much less attention in surface/interfí science, in part due to difficulties encountered in the growth of high quality single crystals. $T$ fundamental research effort in this field has been focused on clean surfaces of cubic and hexagonal $\mathrm{SiC}$, surface oxidation and nitridation and on metal/SiC interface formation $[11,12]$.

One of the major problems with $\mathrm{SiC}$ is the growth of high quality single crystals. Bulk single crys growth has been successfully achieved for the hexagonal phase $(\alpha)$ using the Lely [13] and the modifi Lely [14] methods which have been used and significantly developed in Saint Petersburg (Russia) at $t$ Ioffe Institute and at the Electrotechnical University, and also in many other national laboratories, acaden institutions and industrial companies world wide $[4,5]$. While large (wafers having diameters $\approx 2$ ' and $\mathrm{nc}$ $3^{\prime}$ ) single crystal $4 \mathrm{H}-\mathrm{SiC}$ and $6 \mathrm{H}-\mathrm{SiC}$ wafer could be obtained, this method still leaves a significant dens: of micro-pipes in the bulk of the material which have detrimental effects in device applications. $T$ situation is much more complicated for cubic $(\beta) \mathrm{SiC}$ (or 3C-SiC) crystals for which bulk crystal grow has always resulted in high defect densities. Another approach for cubic silicon carbide crystals is $\mathrm{t}$ growth of $\mathrm{SiC}$ thin films (about $\approx 1 \mu \mathrm{m}$ thick) on a $\mathrm{Si}(100)$ wafer by $\mathrm{C}_{3} \mathrm{H}_{8}$ and $\mathrm{SiH}_{4}$ chemical vap deposition (CVD) on vicinal $\left(4^{\circ}\right) \mathrm{Si}(100)$ wafers [15-18]. This process has been commonly used (NAS Cree, LETI) and achieves single domain $\beta-\mathrm{SiC}(100)$ thin film crystals having much lower defect densities

Almost all $\beta-S i C(100)$ surface and interface studies have been performed on such epitaxially grov $\mathrm{SiC}$ thin films [11,12]. Most of these experimental investigations are based on well established techniqu such as Auger electron spectroscopy (AES), low and high energy electron diffraction (LEED, RHEED), ray photoemission spectroscopy (XPS) and x-ray photoelectron diffraction (XPD) [11,19-28]. Late] more recent techniques as core level and valence band photoemission and absorption spectrocopies usil synchrotron radiation (XPS, UPS, NEXAFS), medium energy ion scattering (MEIS) and scanni tunneling microscopy have been successfully used to investigate the properties of $\beta$-SiC surfaces al 
interfaces [29-36]. Several theoretical studies have also been performed for these systems including both semi-empirical approaches $[37,38]$ and ab-initio methods using the local density functional approximation (LDF) [39-43].

Cubic ( $\beta$ ) silicon carbide ( $\mathrm{SiC}$ ) has the zinc blende structure and is composed of alternating silicon and carbon layers. Its surface, in particular the (100) face, was expected to have very similar overall properties to those of elemental covalent semiconductors such as silicon or germanium. However, unlike Si (Ge), $\beta-\mathrm{SiC}$ is not a fully covalent semiconductor and, due to an underlying Clayer, its (100) face is a polar surface. Therefore, the understanding of $\beta-\mathrm{SiC}(100)$ surface structure is a very important issue while it is challenging to compare similar surfaces having non-polar - $\mathrm{Si}(100)$ versus polar - $\beta$-SiC $(100)$ characters. Furthermore, there is a very large mismatch between silicon and cubic silicon carbide lattice parameters. This situation results in a surface having Si atoms "compressed" by $\approx 20 \%$ on Si-terminated $\beta-S i C(100)$ (when compared to the $\mathrm{Si}(100)$ surface) which cannot be reproduced on any Si surfaces. In this view, the $\beta-\mathrm{SiC}(100)$ might also become a prototypical case for investigations of surface stress effects on surface properties.

In this review article, we will describe and comment some of the latest progress in Si-rich and Siterminated cubic silicon carbide (100) surface knowledge based on advanced experimental techniques such as core level and valence band photoemission spectroscopies (angle integrated) using $\mathrm{x}$-ray and synchrotron radiation sources, atom resolved scanning tunneling microscopy, and state-of-the-art STM image simulations or $a b$-initio total energy theoretical calculations using the local density functional approximation. We will especially address the following issues: i) achieving high quality cubic silicon carbide (100) surfaces, ii) understanding the atomic geometry of Si-rich and Si-terminated surface reconstructions, iii) describing phase transition between surface reconstructions leading to the formation of iv) self-organized $\mathrm{Si}$ atomic one-dimensional sub-nanostructures having fascinating characteristics.

\section{II - SURFACE PREPARATION AND CHARACTERIZATION}

The as-received $\beta-\mathrm{SiC}(100)$ thin film samples are initially covered by native oxides - primarily $\mathrm{SiO}_{2}$ and by an excess of amorphous and graphitic carbon species resulting from the CVD method of growth which have to be removed in first place to get a clean surface. This could be routinely achieved by thermal annealing only. Such a process could be followed using the Si 2p, C 1s and O 1s core levels observed by XPS [28]. One can see from the Si 2p core level (Fig. 2) that, upon thermal annealings of the "as received" $\mathrm{SiC}$ sample between $360^{\circ} \mathrm{C}$ and $1100^{\circ} \mathrm{C}$, the native $\mathrm{Si}$ oxide layer is progressively removed from the surface. This is further confirmed by looking at the $\mathrm{O} 1 \mathrm{~s}$ core level which is completely quenched at $1100^{\circ} \mathrm{C}$. Also, the evolution of the $\mathrm{C}$ is core level for the same sequence (Fig. 2) indicates that the graphitic and amorphous carbon species are also removed after a $1100^{\circ} \mathrm{C}$ annealing, leaving a stoichiometric $\mathrm{SiC}$ surface. The obtained surface is clean and exhibits a surface plasmon (22 eV) feature (Fig. 3) characteristic

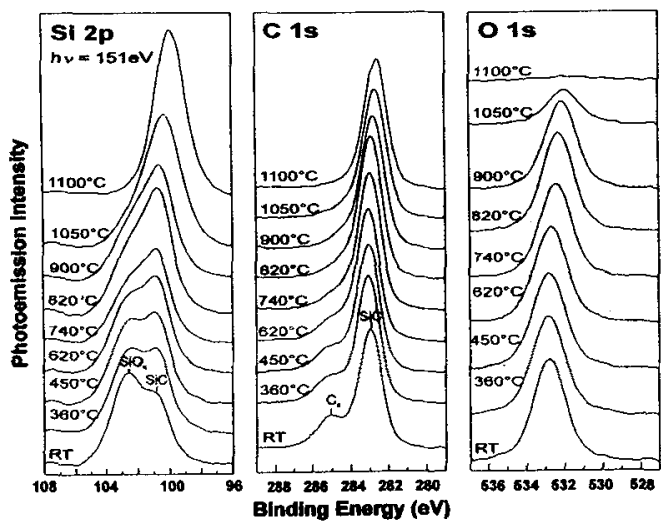

Fig. 2: Si 2p, C 1s and $O$ 1s core levels for the "as received" $\beta$-SiC (100) surface (bottom spectra) and after annealings up to $1100^{\circ} \mathrm{C}$. The photon energies were $151.4 \mathrm{eV}(\mathrm{Si} 2 \mathrm{p})$ and $1,486.6 \mathrm{eV}(\mathrm{C} 1 \mathrm{~s}$ and $O \mathrm{ls})$.

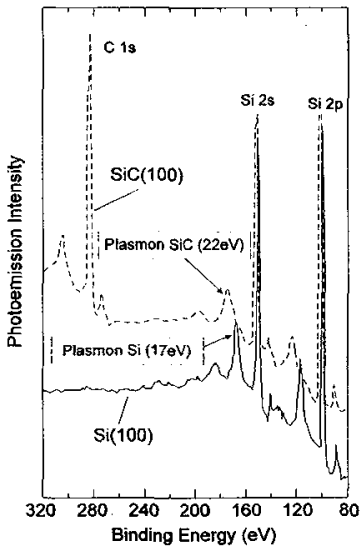

Fig. 3: Wide scan XPS spectra for a $\beta$-SiC (100) (dashed) \& Si(100) (solid) surfaces showing characteristic plasmon losses at Si $2 p$ and C 1s core levels. 

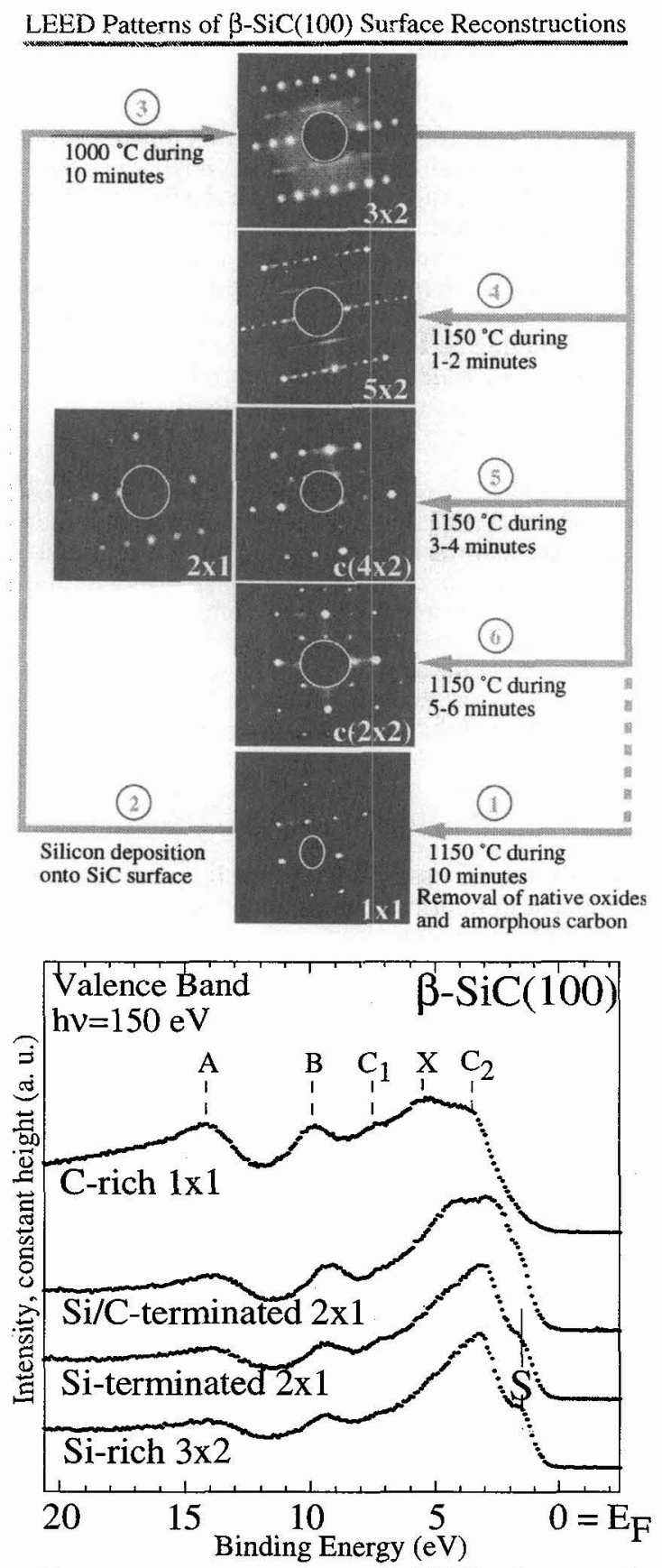

Fig. 4: Sequence of $\beta$-SiC(100) surface preparation with LEED photographs (Top) and valence band spectra (Bottom) corresponding to various surface reconstructions. The valence band spectra exhibit spectral features that are specific of surface reconstruction and composition.

of $\mathrm{SiC}$ [28]. However, the latter surface is not yet ordered and one has to anneal the SiC sample at higher temperatures $\left(\approx 1200^{\circ} \mathrm{C}\right)$ to get a $1 \times 1$ LEED pattern (Fig. 4) [32]. This corresponds to a carbon rich $\beta$ $\mathrm{SiC}(100)$ surface resulting from $\mathrm{Si}$ surface depletion. The silicon stoichiometry is restored by $\mathrm{Si}$ evaporation on the room temperature $\beta-\mathrm{SiC}(100) 1 \times 1$ surface followed by thermal annealing at $1000^{\circ} \mathrm{C}$ 
leading to a $\beta-\mathrm{SiC}(100) 3 \times 2$ (Si-rich) surface reconstruction [32] having a sharp LEED pattern (Fig. 4). Further annealings at slightly higher temperature $\left(1150^{\circ} \mathrm{C}\right)$ during few minutes result in the following surface reconstructions: $5 \times 2,7 \times 2, \ldots .(2 n+1) \times 2$ (corresponding to self-organized Si atomic lines - see below), $c(4 \times 2)$ and $2 \times 1$ (Si-terminated), $c(2 \times 2) \mathrm{C}$-terminated and finally back again to the $1 \times 1$ (C-rich, graphitic) $\beta$-SiC (100) surface (Fig. 4) [32]. This sequence could be repeated again and again, and leads to reproducible $\beta-\mathrm{SiC}(100)$ surface reconstructions that could also be identified by specific spectral features in the valence band - (Fig. 4) and at Si 2 p and C 1s core levels [30-32] - see also below. The valence band spectra for Si-rich and Si-terminated surfaces display an electronic surface state $\mathrm{S}$ located below the Fermi level while the latter is not present for $\mathrm{C}$ containing $\beta-S i C(100)$ surfaces (Fig. 4, bottom). Notice that many groups perform Si deposition at elevated temperatures (several hundred degrees Celsius). Some authors also use $\mathrm{Ar}+$ ion sputtering to remove native oxides and carbon clusters. However, the latter method generally leaves many defects that, unlike most metal surfaces, cannot be removed by thermal annealings.

\section{III - THE Si-RICH $\beta$-SiC(100)3 $\times 2$ SURFACE RECONSTRUCTION}

Based on LEED, Auger, XPS and previous STM experiments, the $3 \times 2$ surface reconstruction was known to a be a Si-rich surface having a Si coverage of $2 / 3$ of a monolayer (ML) $[11,44]$. From these investigations, the $\beta-\mathrm{SiC}(100) 3 \times 2$ surface structure was understood to result from dimer rows in which the dimer direction is parallel to the row [44]. In contrast, medium energy ion scattering (MEIS) and RHEED studies have shown that the Si coverage is 1/3 Si ML [29] which is not consistent with such a picture [44].

The $\beta-\mathrm{SiC}(100) 3 \times 2$ surface structure has been investigated by atom-resolved STM which, unlike diffraction techniques, probes the real space. Fig. 5 shows a representative $400 \AA$ x $400 \AA$ topograph (filled electronic states) of the $\beta-\mathrm{SiC}(100) 3 \times 2$ [35]. First, one should notice the high surface quality that is comparable to $\mathrm{Si}(100) 2 \times 1$ with a low density of defects. The surface includes oval spots originating from individual Si-Si dimers in a $3 \times 2$ array and forming rows [35]. Few defects could also be seen in Fig. 5a including missing dimers, dimers pairs and dimers having a different tilt angle. Dimers pairs are of special interest since it results from two Si dimers separated by a shorter distance [35]. Fig. 5b shows a closer view of defects. Height profiles along axis corresponding to the dimer rows stress better the existence of dimer pairs [35]. This defect is at the origin of dimer row translation by one time the surface lattice parameter, resulting in the formation of antiphase boundaries that could be seen in Figs. 5a and 5b [35]. Additional insights about the $\beta-\operatorname{SiC}(100) 3 \times 2$ surface structure could be found by tunneling into the empty electronic states. Fig. 6 displays such a $200 \AA$ x $200 \AA$ STM topograph in which the two individual Si-atoms belonging to each dimer are identified, clearly showing that dimers are perpendicular to the row direction [35]. A height profile along $y y^{\prime}$ axis shows that the two atoms belonging to the same dimer do not have the same height indicating that dimers are asymmetric [35], in qualitative agreement with ab-initio calculations [40]. Furthermore, all the dimers are seen to be tilted in the same direction, (i.e. not anticorrelated) unlike the dimers forming a $c(4 \times 2)$ reconstruction on $\mathrm{Si}(100) 2 \times 1$ and $\mathrm{Ge}(100) 2 \times 1$ surfaces $[45,46]$.
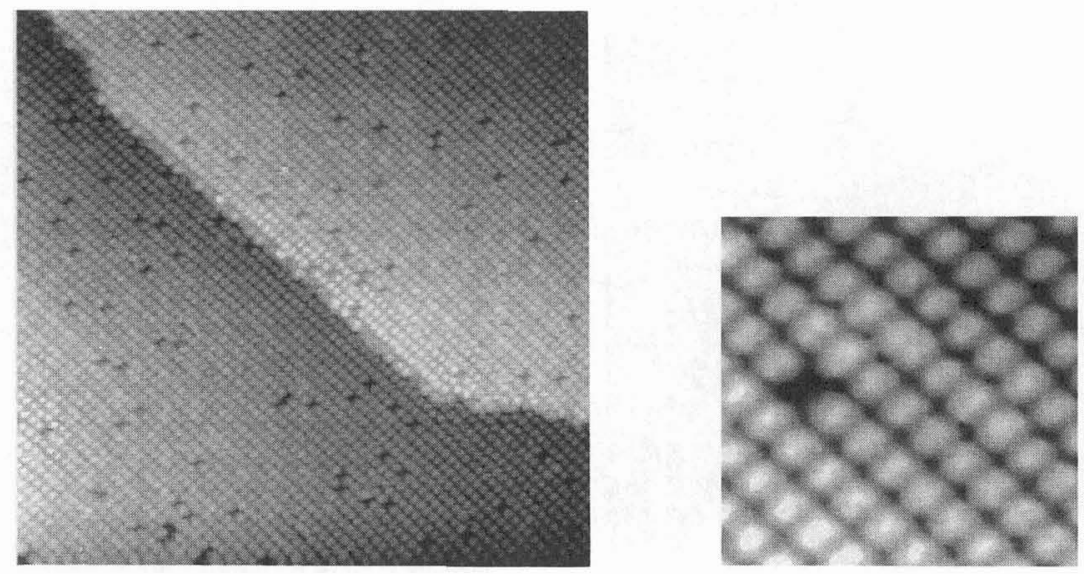

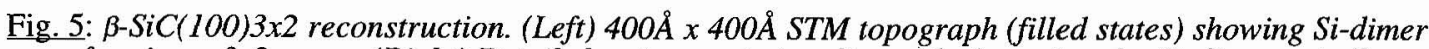
rows forming a $3 \times 2$ array. (Right) Detail showing a missing dimer (dark spot) and a Si-dimer pair (large spot). The latter is at the origin of antiphase boundaries with dimer row translations along the row. 


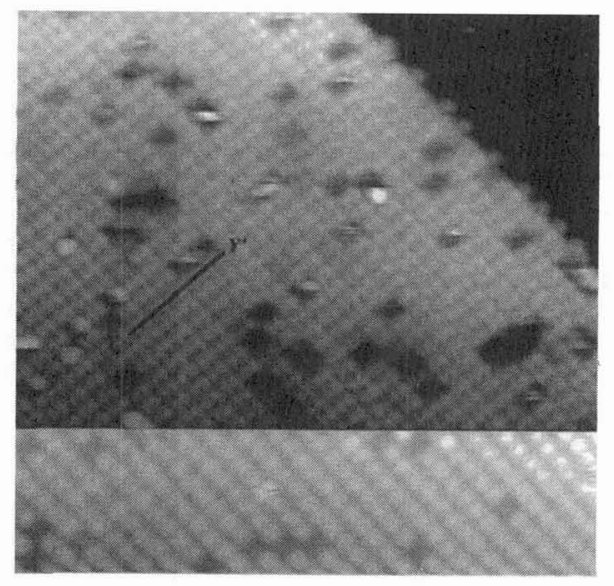

a)

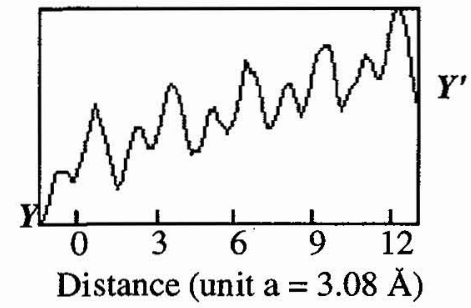

Fig. 6: $200 \AA \times 200 \AA$ STM topograph of the $\beta$-SiC(100)3x2 surface using filled electronic states (bottom) and empty electronic states (top) showing Si atom position. a) Profile along YY' showing the height difference between two Si atoms belonging to the same dimer indicating the asymmetric nature of the latter.

Figures $7 \mathrm{a}$ and $7 \mathrm{~b}$ display $800 \AA$ x $800 \AA$ representative STM topographs of a $\beta-S i C(100) 3 \times 2$ surface which show best the surface morphology $[32,35,47]$. One can see that the surface has large Si islands and terraces at $\approx 2.2 \AA$ height above the surface and having dimer rows all oriented in the same direction in a $3 \times 2$ surface arrangement (Fig. 7a) [35]. Large island vacancies also exist (Fig. 7b) with the same $3 \times 2$ surface structure. This indicates that, when preparing the $3 \times 2$ surface, Si $3 \times 2$ islands are formed followed by island coalescence upon additional Si deposition and thermal annealing sequences [47]. A spectral signature of $\mathrm{Si}$ islands could be found by looking at the $\mathrm{Si} 2 \mathrm{p}$ core level for the $\beta-\mathrm{SiC}(100) 3 \times 2$ surface. Fig. 8 shows Si 2 p core level spectra (surface and bulk sensitive) recorded in photoemission using synchrotron radiation which exhibits 3 features including bulk $B$ and two surface $A$ and $C$ components [48]. While peaks $\mathrm{B}$ and $\mathrm{C}$ are related respectively to the bulk and surface $\mathrm{Si}-\mathrm{C}$ bonds, peak $\mathrm{A}$ is a surface core level shift at a $99.2 \mathrm{eV}$ binding energy (i.e. the binding energy of pure $\mathrm{Si}$ ) indicates surface Si-Si bonds [48]. Recently, very high resolution $(\Delta \mathrm{E} \leq 60 \mathrm{meV})$ core level photoemission spectroscopy experiments have been performed at the Advanced Light Source (Berkeley) [49]. The results show that the Si $2 \mathrm{p}$ core level for the $\beta$-SiC (100) $3 \times 2$ reconstruction exhibits at least 5 components, with 2 of them that could be correlated to the up- and down Si atoms belonging to an asymmetric dimer [49] as observed by STM (Fig. 6) [35].

a)

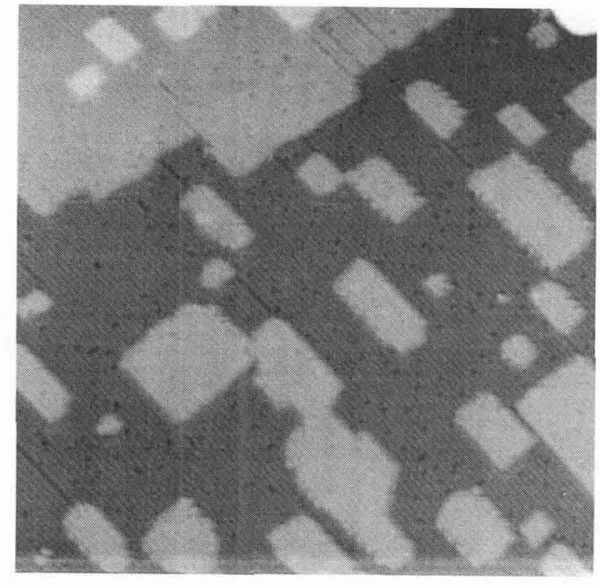

b)

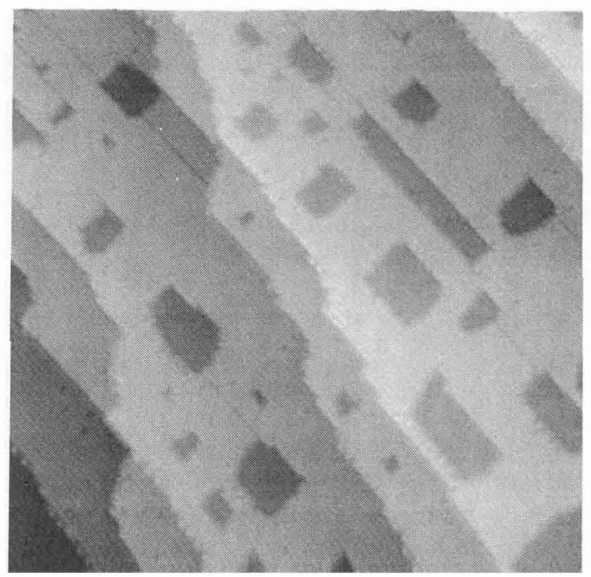

Fig. 7: $800 \AA \times 800 \AA$ STM topographs (filled electronic states) showing the $\beta$-SiC(100)3x2 surface morphology a) Si islands having a $3 \times 2$ array and b) Si vacancies islands also having a $3 \times 2$ array. The "electronic" height of Si islands above the surface is $2.2 \AA$. 


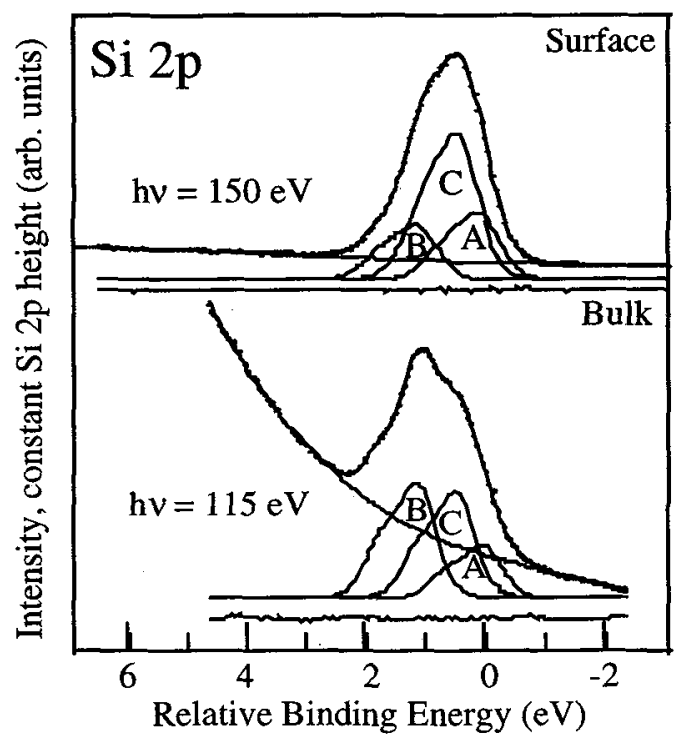

Fig. 8: Si $2 p$ core level shifted components $(A=$ surface Si-Si bonds, $B=$ bulk Si-C bonds and $C=$ surface Si-C bonds), fit, background and residual background for $\beta$-SiC(100) $3 \times 2$ surface in bulk-sensitive mode at a photon energy of $115 \mathrm{eV}$ (bottom) and surface-sensitive mode at a photon energy of $150 \mathrm{eV}$ (top).

\section{IV - THE STOICHIOMETRIC (Si-TERMINATED) $\beta$-SiC(100) $\mathrm{c}(4 \times 2)$ AND $2 \times 1$ RECONSTRUCTIONS}

Due to the expected analogy with the structure of corresponding $\mathrm{Si}(100)$ and $\mathrm{Ge}(100)$ surfaces $[45,46]$, the $\beta-\operatorname{SiC}(100) 2 \times 1$ and $\beta-\operatorname{SiC}(100) \mathrm{c}(4 \times 2)$ surface reconstructions are of special interest. In fact, it was initially believed that the $\beta-\operatorname{SiC}(100) 2 \times 1$ surface reconstruction was the ground state since a $2 \times 1$ LEED pattern has been observed for the stoichiometric Si-terminated surface [11]. c(4x2) LEED photographs have been also observed for Si-terminated surfaces showing the existence of such a reconstruction [11,31] and suggesting a surface structure similar to that of $\mathrm{Si}(100) \mathrm{c}(4 \times 2)$ and $\mathrm{Ge}(100) \mathrm{c}(4 \times 2)$ with anticorrelated asymmetric $\mathrm{Si}-\mathrm{Si}$ (Ge-Ge) dimers $[45,46]$. However, in contrast to these elemental covalent semiconductors which exhibit such a reconstruction at low temperatures only, the $c(4 \times 2)$ array is taking place at room temperature for the $\beta-\operatorname{SiC}(100)$ surface as for the $2 \times 1$ surface reconstruction $[11,31]$. In fact, it was shown that the $\mathrm{Si}(100) \mathrm{c}(4 \times 2)$ exhibits $2 \times 1$ LEED patterns when slightly contaminated or in presence of high defect densities $[11,31]$. Also, one has to keep in mind that the stoichiometric $\beta$-SiC $(100)$ surface is a stressed surface when compared to other semiconductors. In fact, due to the large difference between lattice parameters, the Si atoms on a Si-terminated $\beta-\mathrm{SiC}(100)$ surface are "compressed" by $\approx 20 \%$ when compared to the situation of $\mathrm{Si}(100) 2 \times 1$. This key factor is likely to have major consequences and to result in a very specific surface structure. Also, contrary to the $3 \times 2$ surface reconstruction which is a very open surface with a $1 / 3 \mathrm{Si}$ monolayer coverage [35], the c(4x2) surface is completed at a full 1 monolayer Si coverage $[11,12,29,31]$.

In order to clarify these points, atom resolved scanning tunneling microscopy experiments have been performed [36]. Fig. 9a shows a representative $400 \AA$ x $400 \AA$ STM topograph (filled electronic states). The pattern exhibits a characteristic pseudo-hexagonal array in which each spot represents a Si-Si dimer as confirmed by STM image calculations using the STM Elastic-Scattering Quantum Chemistry (STM-ESQC) method [36]. While this surface seems to present a somewhat higher defect density, it shows only very few antiphase boundaries ( 3 of them can be seen e.g. in Fig. 9) having a length limited to $\leq 50 \AA$ which significantly differs from the behavior of the $3 \times 2$ surface - see above [35]. Fig. $9 \mathrm{~b}$ provides a closer look of this surface: in some area having higher defect densities, on can see that the corrugation deteriorates with an ordering corresponding to a $2 \times 1$ domain [36], in agreement with previous LEED reports [31]. When making dimer height plots along the $\mathrm{XX}^{\prime}$ (perpendicularly to dimer rows) and $\mathrm{YY}^{\prime}$ (along the dimer rows) axis, one can clearly see the existence of additional density of states between two dimers belonging to the same row (Fig. 10). This interesting feature suggests the existence of an additional Si-Si dimer which would be located below the surface between two dimers "visible" to the STM tip [36]. Such a picture of 
dimer rows having up- and down-dimers (AUDD) within a row is strongly supported by the theoretical ESQC-STM height plot calculations performed at constant tunneling current for various up and down dimer height differences $\partial z$ perpendicularly $\left(X^{\prime}\right)$ and along $\left(Y^{\prime}\right)$ the dimer rows. These calculations also indicates that, when the height difference $\partial z$ between the up and the down dimer is above $0.1 \AA$, the down dimer would remain hidden to the STM tip [36].
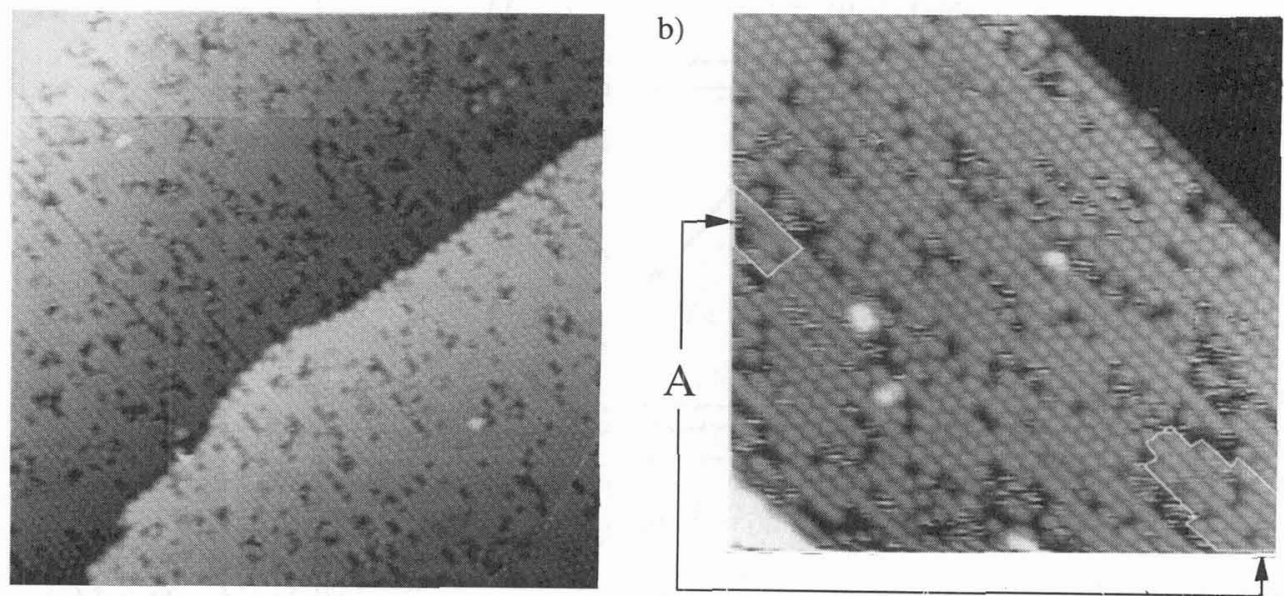

Fig. 9: $\beta$-SiC(100) c(4x2) surface a) $400 \AA x 400 \AA$ STM topograph (filled states) and b) $200 \AA x 200 \AA$ STM topograph (filled states) showing some areas (marked A) having lower corrugations with a $2 x 1$ array.

$\begin{array}{lll}\text { a) Experimental } & \text { Scan } X X^{\prime} & \text { b) Theoretical }\end{array}$
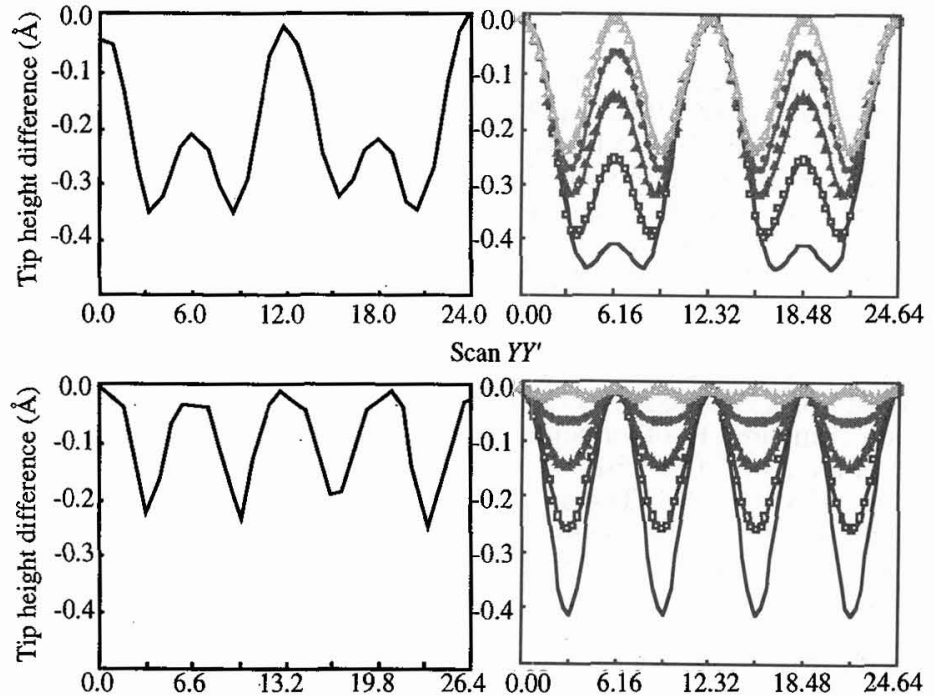

$$
\begin{aligned}
&-\Theta=0.5 \mathrm{ML} \\
&-\Theta=1 \mathrm{ML}, \delta \mathrm{z}=0.1 \AA \\
& \downarrow \Theta=1 \mathrm{ML}, \delta \mathrm{z}=0.05 \AA \\
&-\Theta=1 \mathrm{ML}, \delta \mathrm{z}=0.02 \AA \\
&-\Theta=1 \mathrm{ML}, \delta \mathrm{z}=0.0 \AA
\end{aligned}
$$

Fig. 10: a) Experimental height profiles along the dimer row $Y Y^{\prime}$ axis (bottom) showing two components corresponding to up-and down-dimers, and perpendicular to the dimer row XX' axis (top) showing the component corresponding to up-and down-dimers; b) Theoretical height profiles at constant tunneling current using STM-ESQC method for various up/down dimer height differences $\partial \mathrm{z}$ along $X X^{\prime} \& Y^{\prime} Y^{\prime}$ axis. 
Experimental Topograph

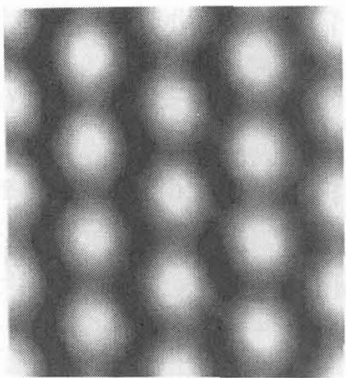

ESQC - STM Theoretical Image Simulation

Fig. 11: Details of a STM topograph showing the pseudo-hexagonal dimer array of the c(4x2) surface reconstruction (Left). Simulated STM image calculated from the theoretical height profiles at constant tunneling current using the STM-ESQC method (Right).

These STM results indicates that the $c(4 \times 2)$ surface reconstruction results from dimer rows having up- and down-dimer (AUDD) within a row in an arrangement reducing the very large surface stress. A model of this reconstruction is provided in Fig. 12 also displaying the corresponding experimental and calculated STM images [36]. Incidentally, one should notice the excellent agreement between the STM topograph and the calculated image [36]. Such an AUDD surface structural model has never been observed for any other surface reconstructions. Furthermore, the structure of the $\beta-\operatorname{SiC}(100) \mathrm{c}(4 \times 2)$ reconstruction (AUDD) is very different from that of corresponding elemental semiconductors as $\mathrm{Si}(100) \mathrm{c}(4 \times 2)$ and $\mathrm{Ge}(100) \mathrm{c}(4 \times 2)[45,46]$. In fact, contrary to the case of covalent semiconductor surfaces in which dangling bond reduction is at the origin of surface reconstructions, surface stress reduction is the leading driving force in this AUDD surface arrangement resulting in a c $(4 \times 2)$ array [36]. This also explains why $2 \times 1$ surface domains are found in area having higher defect densities [36]. In this case, defects and/or vacancies would locally release the surface stress allowing to have the up- and down-dimers coming at the same height [36]. This explains why the $2 \times 1$ surface was initially found in pioneer works to be the ground state of the stoichiometric Si-terminated $\beta$-SiC $(100)$ surface reconstruction [36]. Actually, the $2 \times 1$ surface results from a failed $c(4 \times 2)$ surface reconstruction. This AUDD structure for the $c(4 \times 2)$ surface reconstruction is further supported by the first theoretical work recently performed for this surface by $a b$-initio total energy calculations using the LDF approach in which the surface is represented by large clusters having up to 137 atoms [50]. $\beta$-SiC $(100) \mathrm{c}(4 \times 2)$ could be considered as a model system to study the effects of surface strain.
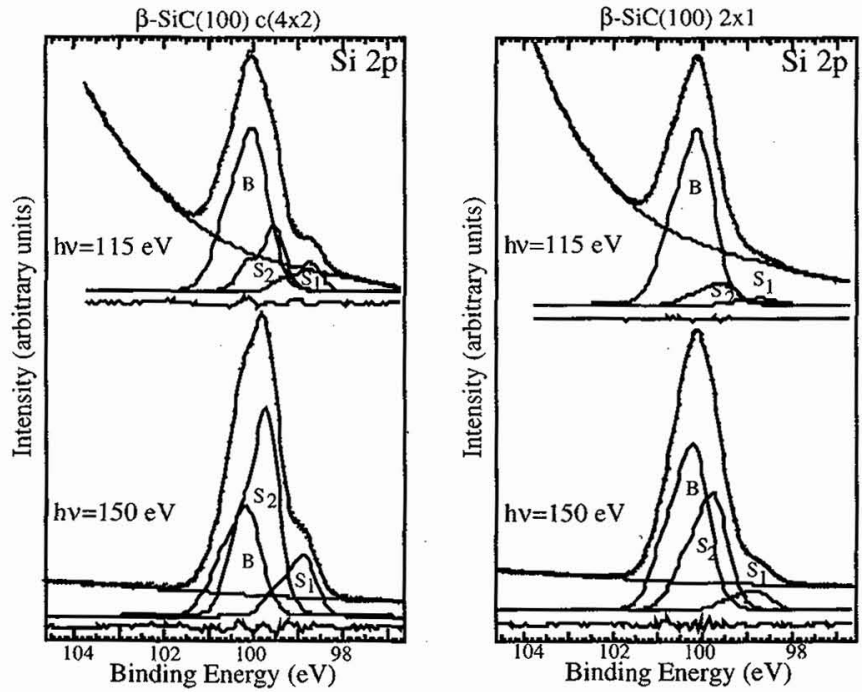

Fig. 12: Si $2 p$ core level shifted components ( $S 1$ and $S 2=$ surface, $B=$ bulk), fit, background and residual background for the c (4x2) (Left) and $2 x I$ (Right) $\beta$-SiC(100) surface reconstructions recorded in bulk-and surface-sensitive modes at photon energies of $150 \mathrm{eV}$ (bottom) and $115 \mathrm{eV}$ (top) respectively. 
We now look at the spectral features that are characteristic of the Si-terminated $c(4 \times 2)$ and $2 \times 1$ surfaces. Figure 12 displays a representative set of $\mathrm{Si} 2 \mathrm{p}$ core levels recorded in surface- and bulk-sensitive modes at photon energies of $150 \mathrm{eV}$ and $115 \mathrm{eV}$ respectively for the $\beta-\mathrm{SiC}(100) \mathrm{c}(4 \times 2)$ and $\beta-\mathrm{SiC}(100) 2 \times 1$ surfaces $[32,50]$. The shape and the spectral features are in excellent agreement with other core level photoemission spectroscopy experiments using synchrotron radiation [31], even for those performed at high energy resolutions [49]. The surface component $S 1$ is of particular interest since this feature is characteristic of the $c(4 \times 2)$ surface reconstruction and is likely related to the $\mathrm{Si}$ atoms belonging to the updimers [36]. It is also visible on the $2 \times 1$ surface with, however, a lower intensity. Additional thermal annealings of the $2 \times 1$ surface reconstrution leads to the removal of this $S 1$ surface component in the Si $2 p$ core level and the appearance of a surface shifted component at the $C 1$ s core level [51]. This shows that upon increasing temperatures, $\mathrm{Si}$ atoms are removed resulting in defects and/or vacancies and $\mathrm{C}$ atoms at the surface [51]. This results in a large variety of $\beta-S i C(100)$ surfaces exhibiting a $2 \times 1$ LEED pattern and having different $\mathrm{Si} / \mathrm{C}$ stoichiometries [51], which stresses the fact that it is difficult to define a $2 \times 1$ surface on the basis of LEED patterns only.

\section{V - SELF-ORGANIZED Si ATOMIC LINES FORMATION ON THE $\beta$-SiC(100) SURFACE}

We now look at the phase transition between the $3 \times 2$ and the $c(4 \times 2)$ surface reconstruction. This is achieved by removal of Si from the $3 \times 2$ surface by thermal annealing. Fig. 13a shows a $800 \AA$ x $800 \AA$ STM topograph obtained after thermal annealing at $1150^{\circ} \mathrm{C}$ of a $\beta-\mathrm{SiC}(100) 3 \times 2$ surface reconstruction [52]. One can discover the striking presence of one dimensional features that are very long $(>1100 \AA)$. A closer look at theses lines in Fig. 13b, which displays a $200 \AA$ x $200 \AA$ STM topograph having a single atomic line, indicates that they are formed of Si-Si dimers [52]. These Si-dimer lines, which are lying on the $c(4 \times 2)$ surface, create on the latter antiphase boundaries between $c(4 \times 2)$ AUDD dimer rows [52]. The length of these sub-nanostructures is basically limited by the substrate only. The number of atomic lines could be mediated by annealing time and temperature, inducing selective Si atom removal which results in arrangements ranging from a very large superlattice (having $5 \times 2,7 \times 2, \ldots .(2 n+1) \times 2$ (with $n \geq 2$ ) surface arrays) to an isolated single Si-atomic line [52]. Interestingly, these lines are not destroyed after annealings below $1000^{\circ} \mathrm{C}$ which demonstrates their very high stability, especially when compared to other types of nanostructure. Finally, one should also remark that these Si atomic lines are self organizing on the surface of a wide band gap material which could be advantageous for conductivity measurements. All these characteristics are unprecedented [52]. In addition to its many advanced properties in domains as different as microelectronics, mechanics and biocompatibility, these findings show very novel and interesting aspects of silicon carbide in its ability to also be a material especially suitable in nanotechnologies.
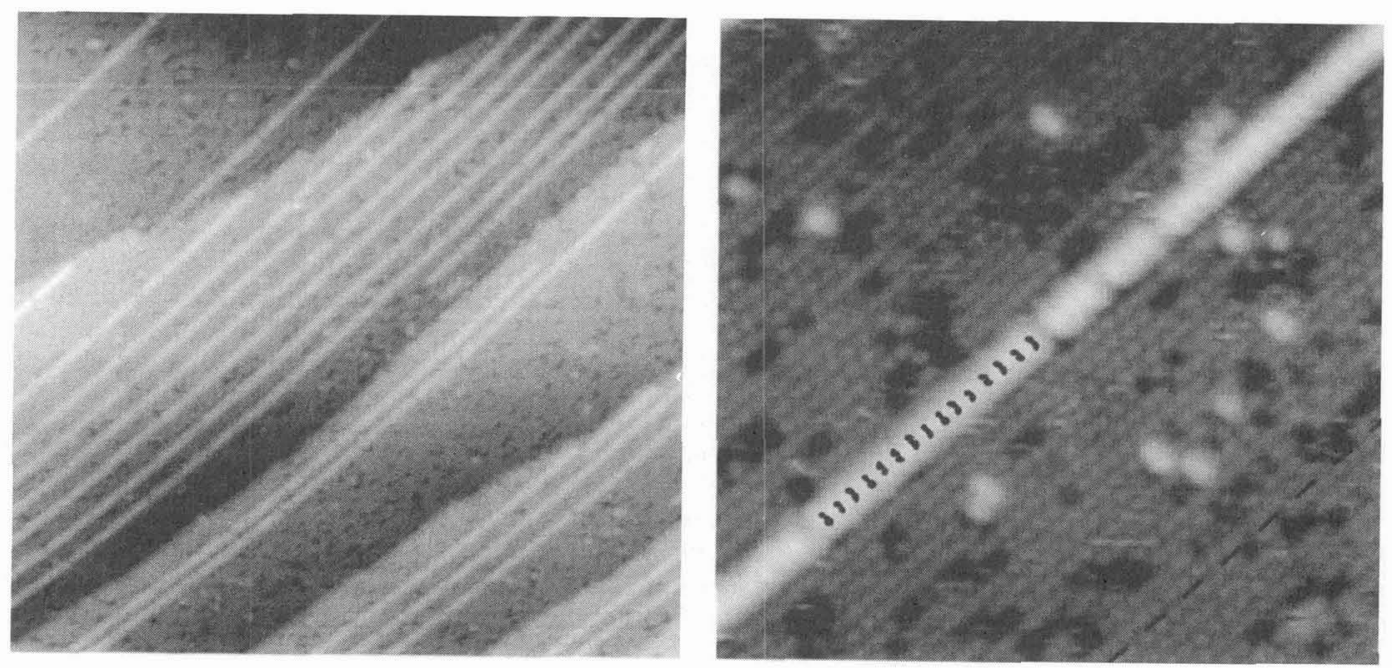

Fig. 13: $800 \AA \times 800 \AA$ STM topographs of Si atomic lines obtained on $\beta$-SiC(100) surface after annealing $a t \approx 1100^{\circ} \mathrm{C}$ (Left). $200 \AA \times 200 \AA S T M$ topograph showing an isolated single Si-atomic line on the $\beta$ $\mathrm{SiC}(100) \mathrm{c}(4 \times 2)$ surface obtained after annealing at $T \leq 1150^{\circ} \mathrm{C}$ with Si-dimers represented schematically (Right). The $c(4 \times 2)$ dimer row direction is shown by a dashed line in the top-right hand side corner. 


\section{VI - CONCLUSIONS}

In summary, we have reviewed the latest developments in preparing and understanding cubic silicon carbide surfaces. Thanks to the use of advanced experimental probes such as synchrotron radiation related techniques, scanning tunneling microscopy, and state-of-the-art theory such as computational STM images or $a b$-initio LDF calculations, it is now possible to have very high quality $\beta$-SiC $(100)$ surfaces at the atomic level and to understand their atomic geometry. These recent investigations have allowed deeper understanding about the growth and the structure of Si-rich and Si-terminated surface reconstructions. Figure 14 displays the schematic models of the $\beta-S i C(100) 3 \times 2$ and $\beta-S i C(100) c(4 \times 2)$ surface reconstructions. The $\beta-\mathrm{SiC}(100) 3 \times 2$ surface reconstruction includes dimer rows having parallel asymmetric

Side View

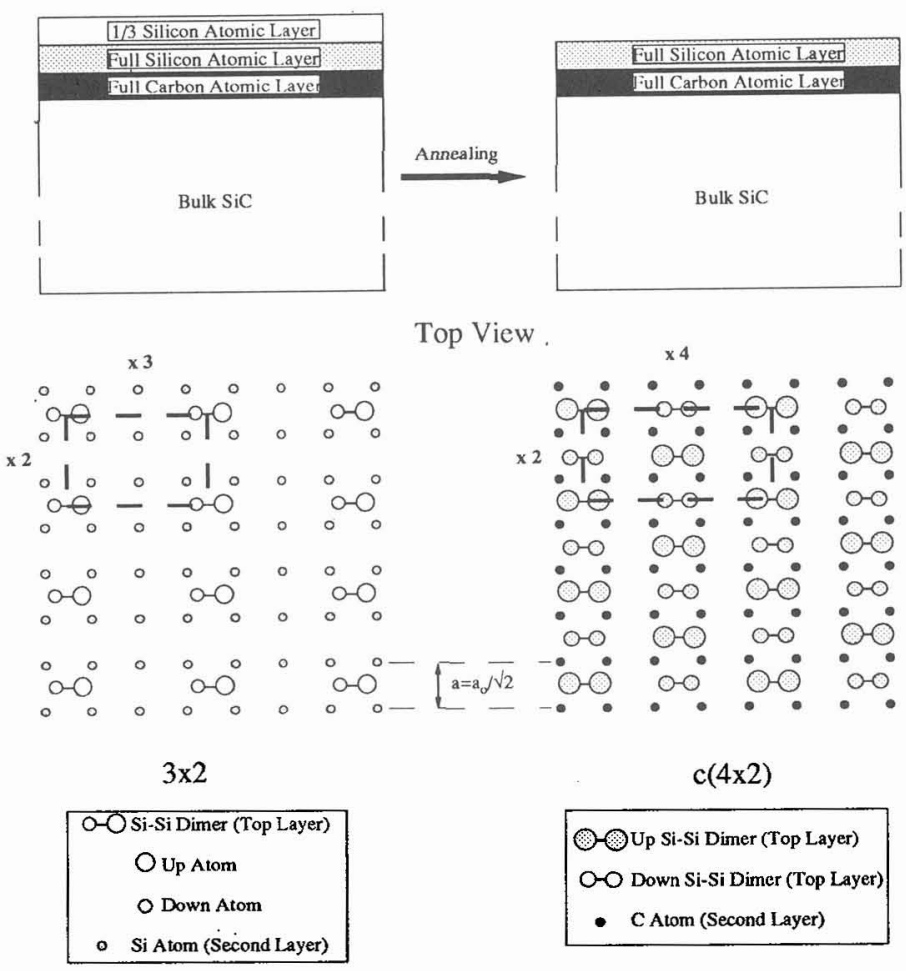

Fig. 14: Schematic and surface structure of (left) $\beta$-SiC(100) $3 \times 2$ (parallel asymmetric dimer (PAS) rows) and (right) $\beta-S i C(100) c(4 \times 2)$ (AUDD ordering) surface reconstructions showing the Si-dimer ordering. Only the two top layers are shown in the top views, the second layer being presented with bulk array. Dashed contours correspond to surface unit cells and $a_{0}\left(a_{0}=4.36 \AA\right)$ is the $\beta$-SiC lattice parameter.

dimers (PAS) all tilted in the same direction perpendicularly to the row [35] at a $1 / 3$ monolayer Si coverage which gives a very "open" surface. The $\beta$-SiC $(100) c(4 \times 2)$ reconstruction which is covered by a full $1 \mathrm{Si}$ monolayer results from dimer rows having alternately up- and down- dimers (AUDD) within a row in an arrangement reducing the large surface stress which indicates that the latter is the leading driving force in the AUDD surface ordering [36]. Contrary to previous beliefs, the characteristics and properties of these surfaces are very different from the (100) surfaces of elemental semiconductors such as silicon or germanium. From a fundamental point of view, the $\beta$-SiC $(100)$ surface is, in this way, a model surface especially suitable to study the effect of strain on surface ordering. Finally, the discovery of self-organized Si-atomic lines that are formed at the phase transition between the $3 \times 2$ and $c(4 \times 2)$ reconstruction brings an additional and novel aspect of silicon carbide [52]. These one dimensional sub-nanostructures, which are made of $\mathrm{Si}$-Si dimers, have unprecendeted characteristics with a very high thermal stability. They represented a new method to achieve one dimensional atomic nano-objects in a single step which could potentially be very useful in nanotechnologies, especially for micro/nano-electronics of the future. 


\section{Acknowledgments}

The authors are grateful to F. Amy, B. Delley, L. Douillard, G. Dujardin, D. Dunham, S. Dupont, C. Joachim, P.S. Mangat, A. Mayne, L. Pizzagalli, M. Riehl-Chudoba, S. Rivillon and E. Wimmer. We also want to thank L. di Cioccio, C. Jaussaud and C. Pudda at LETI (CEA - Technologies Avancées, Grenoble) for providing $\beta$-SiC $(100)$ samples. The STM experiments were performed at the Laboratoire de Photophysique Moléculaire (CNRS) in Orsay. The synchrotron radiation experiments were supported by the U.S. National Science Foundation (NSF) under contract $N^{\circ}$ DMR $92-23710$ through the Northern Illinois University and the Northern Illinois Graduate School Funds. They were performed at the Ednor Rowe Synchrotron Radiation Center, University of Wisconsin-Madison which is supported by NSF under contract $\mathrm{N}^{\circ}$ DMR 92-12658.

\section{References}

1 R.F. Davis, J. Vac. Sci. Technol. A 11 (1993) 829.

2 H. Morkoç, S. Strite, G.B. Gao, M.E. Lin, B. Sverdlov and M. Burns, J. Appl. Phys. 76 (1994) 1363.

3 P.A. Ivanov and V.E. Chelnokov, Semicond. 29 (1995) 1003.

4 Properties of Silicon Carbide, G. Harris editor, EMIS Datareview series, INSPEC (London), Vol. 13, (1995).

5 Silicon Carbide Electronic Devices and Materials, Materials Research Society Bulletin, Vol. 22 (1997) March.

$6 \quad$ R.W. Keyes, Proc. IEEE 60 (1972) 225.

7 E.O. Johnson, RCA Rev. 26 (1965) 163.

8 F. Bozso, L. Muehlhoff, M. Trenary, W.J. Choyke and J.T. Yates, Jr., J. Vac. Sci. Technol. A 2 (1984) 1271; and references therein.

9 J.C. Bokros, R.J. Akins, H.S. Shim, A.D. Hanbold and N.K. Agarwal, Chem. Technol. 7 (1977) 40.

10 K.L. Smith and K.M. Black, J. Vac. Sci. Technol. A 2, 744 (1984).

11 R. Kaplan and V.M. Bermudez, in Properties of Silicon Carbide, G. Harris editor, EMIS Datareview series, INSPEC (London), Vol. 13 (1995) 101; and references therein.

12 V.M. Bermudez, Phys. Stat. Sol. b 202 (1997) 447; and references therein.

13 J.A. Lely, Ber. Deut. Cerman. Ges. 32 (1955) 229.

14 Yu. M. Tairov and V.F. Tsvetkov, J. Cryst. Growth 43 (1978) 209.

15 S. Nishino in Properties of Silicon Carbide, G. Harris editor, EMIS Datareview series, INSPEC (London), Vol. 13 (1995) 204.

16 S. Nishino, Y. Hazuki, H. Matsunami and T. Tanaka, J. Electrocem. Soc. 127 (1980) 2674.

17 S. Nishino, J.A. Powell and H.A. Will, Appl. Phys. Lett. 42 (1983) 460.

18 A. Adamiano and J.A. Sprague, Appl. Phys. Lett. 44 (1984) 525.

19 M. Dayan, J. Vac. Sci. Technol. A 4, 38 (1985).

20 Y. Mizokawa, K.M. Geib and C.W. Wilmsen, J. Vac. Sci. Technol. A 4 (1986) 1696.

21 T.M. Parrill and V.M. Bermudez, Sol. Stat. Commun. 63 (1987) 231.

22 R. Kaplan, Surf. Sci. 215 (1989) 111.

23 J.M. Powers, A. Wander, P.J. Rous, M.A. Van Hove and G.A. Somorjai, Phys. Rev. B 44 (1991) 11159.

24 T.N. Parrill and Y.W. Chung, Surf. Sci. 243 (1991) 96.

25 V.M. Bermudez and R. Kaplan, Phys. Rev. B 44 (1991) 11149.

26 J.M. Powers, A. Wander, M.A. van Hove and G.A. Somorjai, Surf. Sci. Lett. 260 (1992) L 7.

27 M. Diani, J.L. Bischoff, L. Kubler and D. Bolmont, Appl. Surf. Sci. 68 (1993) 575.

28 M. Riehl-Chudoba, P. Soukiassian, C. Jaussaud and S. Dupont, Phys. Rev. B 51 (1995) 14300.

29 S. Hara, W.F.J. Slijkerman, J.F. van der Veen; I. Ohdomari, S. Misawa, E. Sakuma and S. Yoshida, Surf. Sci. Lett. 231 (1990) L 196; T. Yoshinobu, l. Izumikawa, H. Mitsui, T. Fuyuki and H. Matsunami, Appl. Phys. Lett. 59 (1991) 2844.

30 V.M. Bermudez and J.P. Long, Appl. Phys. Lett. 66 (1995) 475.

31 M.L. Shek, Surf. Sci. 349 (1996) 317.

32 F. Semond, Thèse de Doctorat (PhD), Université de Paris-Sud/Orsay, (1996) 19 December.

33 J.P. Long, V.M. Bermudez and D.E. Ramaker, Phys. Rev. Lett. 76 (1996) 991.

34 C.S. Chang, N.J. Zheng, I.S.T. Tsong, Y.C. Wang and R.F. Davis, J. Amer. Ceram. Soc. 73, (1990) 3264; J. Vac. Sci. Technol. B 9 (1991) 681.

35 F. Semond, P. Soukiassian, A. Mayne, G. Dujardin, L. Douillard and C. Jaussaud, Phys. Rev. Lett. 77 (1996) 2013. 
36 P. Soukiassian, F. Semond, L. Douillard, A. Mayne, G. Dujardin, L. Pizzagalli and C. Joachim, Phys. Rev. Lett. 78 (1997) 907.

37 P. Badziag, Surf. Sci. 236 (1990) 48; Phys. Rev. B 44 (1991) 11143.

38 B.I. Craig and P.V. Smith, Surf. Sci. 233 (1992) 255.

39 P. Käckell, B. Wenzien and F. Bechstedt, Phys. Rev. B 50 (1994) 10761.

40 H. Yan, A.P. Smith and H. Jónsson, Surf. Sci. 330 (1995) 265.

41 M. Sabisch, P. Krüger, A. Mazur, M. Rohlfing and J. Pollmann, Phys. Rev. B 53 (1996) 13121.

42 P. Käckell, J. Furthmüller and F. Bechstedt, Appl. Surf. Sci. 104-105 (1996) 45.

43 A. Catellani, G. Galli and F. Gygi, Phys. Rev. Lett. 77 (1996) 5090.

44 S. Hara, S. Misawa, S. Yoshida and Y. Aoyagi, Phy. Rev. B 50 (1994) 4548.

45 C.B. Duke, Chem. Rev. 96 (1996) 1237; and references therein.

46 J.A. Kubby and J.J. Boland, Surf. Sci. Rep. 26 (1996) 63; and references therein.

47 F. Semond, L. Douillard, P. Soukiassian, A. Mayne and G. Dujardin, Surf. Rev. Lett. 5, in press.

48 F. Semond, L. Douillard, P. Soukiassian, D. Dunham, F. Amy and S. Rivillon, Appl. Phys. Lett. 68 (1996) 2144.

49 D. Dunham, P. Soukiassian, J.D. Dennlinger, B.P. Tonner and E. Rotenberg, recent synchrotron radiation results (ALS, Berkeley).

50 In addition to supporting the alternately up-and down-dimer (AUDD) model [36] for the c(4x2) $\beta$-SiC(100) surface reconstruction, total energy ab-initio DMol cluster calculations reveal that the Si-Si dimers have also alternating lengths with the up-dimer being longer that the down-dimer;

L. Douillard, B. Delley, P. Soukiassian and E. Wimmer, recent $a b$-initio DMol calculations.

51 L. Douillard, F. Semond, P. Soukiassian, D. Dunham, F. Amy, S. Rivillon and Z. Hurych, Surf. Rev. Lett. 5 , in press.

52 P. Soukiassian, F. Semond, A. Mayne and G. Dujardin, Phys. Rev. Lett. 79 (1997) 2498. 